\title{
Maintenance of the Normal Flora of Human Skin Grafts Transplanted to Mice
}

\author{
By JOHN N. KEARNEY, ${ }^{1 *}$ G. GOWLAND, ${ }^{1}$ K. T. HOLLAND ${ }^{2}$ AND \\ W. J. CUNLIFFE 3 \\ Departments of ${ }^{1}$ Immunology, ${ }^{2}$ Microbiology and ${ }^{3}$ Dermatology, University of Leeds, \\ Leeds LS2 9JT, U.K.
}

(Received 21 January 1982)

\begin{abstract}
Full-thickness human cadaver skin was maintained on the dorso-lateral thoracic region of hairless mice whose immune rejection mechanism was suppressed using anti-mouse-thymocyte globulin. The bacterial profile of the pregrafted skin did not differ significantly from the normal human microflora. In contrast, the murine skin exhibited quantitative and qualitative differences from the human flora, in particular by the complete absence of Propionibacterium acnes, the dominant bacterium on sebum-rich areas of human skin. The normal microbial profile of the human grafts was maintained throughout the experimental period despite the novel environmental milieu. There was little contamination of the grafts from the normal murine flora. It was concluded that the grafted human skin would provide a realistic model for studying the ecology of human cutaneous micro-organisms.
\end{abstract}

\section{INTRODUCTION}

Most of the information concerning the ecology of the normal microflora of human skin has been obtained by sampling human volunteers (Noble, 1981). A wide variety of techniques have been used to remove the micro-organisms from the skin including contact plates (Somerville \& Noble, 1973), swabbing (Shaw et al., 1970), scrub methods (Williamson \& Kligman, 1965) and the use of contact adhesives (Holland et al., 1974). These methods provide relative estimates of the microbial densities. Only by the removal of whole skin biopsies have absolute estimates been obtained (Puhvel et al., 1975); however, this technique has justifiable ethical restrictions.

Because ecological systems are very complex and only a limited understanding of the 'laws' governing their component populations has been achieved, the application of the in vitro reductionist approach to their investigation has not proved very useful. The resulting laboratory models achieve a high degree of precision, at the expense of sacrificing generality and reality (Levins, 1968).

A more profitable approach has been to investigate the normal functioning of the system in vivo, and to observe the consequences of natural or experimentally induced perturbations to the system, including the effects of puberty (Leyden et al., 1975), the introduction of natural antibiotic-producing bacteria (Aly et al., 1974) and the application of selective antibiotics (Leyden \& Marples, 1973). Again, however, there is a limit to the type of probe used to investigate the functional relationships of the component species, and to the type of perturbation that can be used in vivo. Radioactive markers, chemical mutagens, pathogenic microorganisms, etc. and even certain antibiotics cannot normally be considered. It is therefore essential to have a realistic model system, not relying on volunteers, if ecological studies are to progress. A skin graft model designed for this purpose has been described (J. N. Kearney, G. Gowland, K. T. Holland \& W. J. Cunliffe, unpublished). The purpose of the present investigation was to assess the resilience of the microbial ecosystem of human skin grafts to the grafting procedure and to the novel microbial and physiological environment encountered on the host organism. The results would determine whether the system was sufficiently realistic to be a 
useful model and should also provide ecological information on its response to these perturbations.

\section{METHODS}

Skin grafting. The methods of free skin grafting and immunological suppression have been described in detail previously (J. N. Kearney, G. Gowland, K. T. Holland \& W. J. Cunliffe, unpublished; Billingham \& Medawar, 1951). Briefly, human cadaver skin from the mid-thoracic region was cut to $1.5-2.0 \mathrm{~mm}$ thickness with a sterile Castroveijo electrokeratome and placed on filter paper soaked in sterile $0.9 \%(\mathrm{w} / \mathrm{v}) \mathrm{NaCl}$ solution (Phoenix Pharmaceuticals, U.K.). The skin was obtained within $36 \mathrm{~h}$ of death, during which time the cadaver was maintained at $4{ }^{\circ} \mathrm{C}$. The sheet of skin was cut into graft-sized pieces (approx. $1 \mathrm{~cm}^{2}$ ) and immediately used for microbiological assessment and in transplantation. Each graft was transferred to a graft bed cut into the dorsolateral thoracic surface of a hairless mouse, covered with a sterile vaseline-impregnated tulle gras, and the whole thoracic region was encased by a plastercast. This was left in place for $7 \mathrm{~d}$ to permit vascularization of the graft, after which plaster and tulle gras were removed. Any graft showing signs of infection was not used.

Comparison of the human graft flora with the murine flora. Batches of mice were sacrificed by spinal dislocation at varying time intervals post-grafting. Pieces of mouse skin $\left(1 \mathrm{~cm}^{2}\right)$ were excised from both the anterior occluded and posterior non-occluded dorso-lateral surfaces, in addition to the excision of the human graft. The skin was soaked in sterile $1 \mathrm{M}-\mathrm{CaCl}_{2}$ for $2 \mathrm{~h}$ to facilitate the separation of the epidermis with attached follicles from the dermis (Kellum, 1966). The epidermal portion was ground in a micro-tissue homogenizer (Pierce Chemical Co., Ill., U.S.A., $0.2 \mathrm{ml}$ glass/glass) in half-strength wash fluid (Williamson \& Kligman, 1965) to release microorganisms. Tenfold serial dilutions of this suspension in half-strength wash fluid were plated on the following media. (1) Heated blood agar: defibrinated horse blood (Oxoid; $50 \mathrm{ml} \mathrm{l}^{-1}$ ), blood agar base (Oxoid; $40 \mathrm{~g} \mathrm{l}^{-1}$ ). (2) McConkey agar (Oxoid). (3) Aerobic coryneform medium (J. Leeming, personal communication): defibrinated horse blood $\left(50 \mathrm{ml} \mathrm{l}^{-1}\right)$, blood agar base $\left(40 \mathrm{~g} \mathrm{l}^{-1}\right)$, glucose $\left(2 \mathrm{~g} \mathrm{l}^{-1}\right)$, yeast extract (Oxoid; $\left.3 \mathrm{~g} \mathrm{l}^{-1}\right)$ Tween 80 $\left(2 \mathrm{ml} \mathrm{l}^{-1}\right.$ ). (4) Nutrient agar (Oxoid). (5) Reinforced clostridial medium (RCM; Oxoid). (6) RCM with $6 \mu \mathrm{g} \mathrm{ml}^{-1}$ furoxone to inhibit the anaerobic growth of staphylococci (Cove \& Eady, 1982).

Media 1-4 were incubated aerobically, 5 and 6 anaerobically at $37^{\circ} \mathrm{C}$. The same technique was used for pregrafted human skin. The results are expressed as mean $\log _{10}$ (c.f.u. $\mathrm{cm}^{-2}$ ).

Representative isolates of all microbial types were assigned to genus or broader grouping on the basis of growth and colonial morphology on the various media, cell morphology and Gram reaction. Staphylococci were typed by the scheme of Kloos \& Schleifer (1975), and propionibacteria by the method of Marples \& McGinley (1974).

Temporal changes in the density of propionibacteria and staphylococci on human skin grafts. A series of experiments were carried out to determine in more detail the temporal changes in the two major genera found on human grafts, the propionibacteria and staphylococci. Each experiment consisted of grafting up to 15 mice with skin derived from one cadaver and determining the densities of these two bacterial genera immediately and at different intervals post grafting. The densities prior to grafting for each cadaver, and hence for each experiment, were markedly different. To permit pooling of results from many experiments the change in $\log _{10}$ (number of bacteria) was computed for each graft compared with the density prior to grafting for that particular cadaver skin. This analysis assumes that the magnitude of any change in density will be independent of the initial density. There was no indication from the data that this assumption was invalid.

\section{RESULTS}

Human cadaver skin. The microflora of thoracic cadaver skin (Fig. 1) was essentially the same as found on normal human skin (Noble, 1981), with a preponderance of propionibacteria and staphylococci.

Murine skin. It has previously been shown that the anterior and posterior regions of hairless mice carry identical floras (J. N. Kearney, G. Gowland, K. T. Holland \& W. J. Cunliffe, unpublished). The posterior region was therefore used as a control for comparison with the anterior occluded mouse skin (Fig. 2). At both $7 \mathrm{~d}$ (Fig. 2a,b) and $9 \mathrm{~d}$ (Fig. 2c,d) post grafting, there was no significant difference between occluded and non-occluded mouse skin in the carriage of any microbial type. The dominant organisms on mice were the aerobic coryneforms and staphylococci. There was a higher carriage of staphylococci at $7 \mathrm{~d}$ than at $9 \mathrm{~d}$ post grafting on both occluded and non-occluded skin.

Comparison of the human graft flora with the murine flora. At $7 \mathrm{~d}$ post grafting, the human skin maintained a high carriage of Propionibacterium acnes (Fig. 2a), a species not present on mouse 


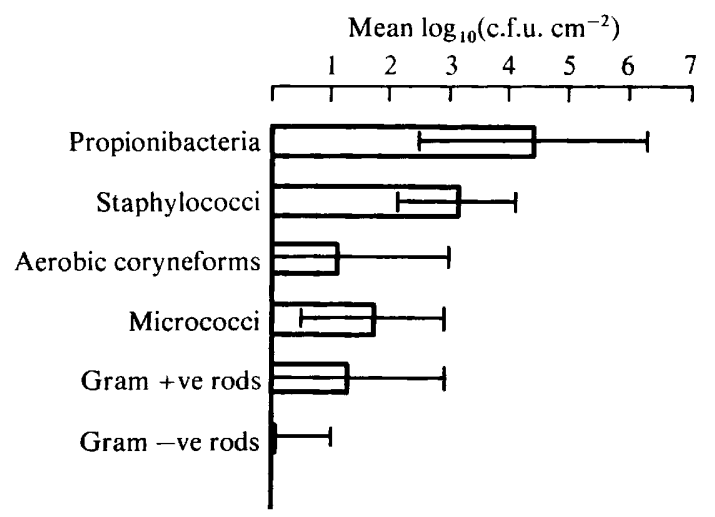

Fig. 1. Density of micro-organisms on human thoracic cadaver skin [mean $\log _{10}$ (c.f.u. $\mathrm{cm}^{-2}$ ) $\pm 95 \%$ confidence limits].

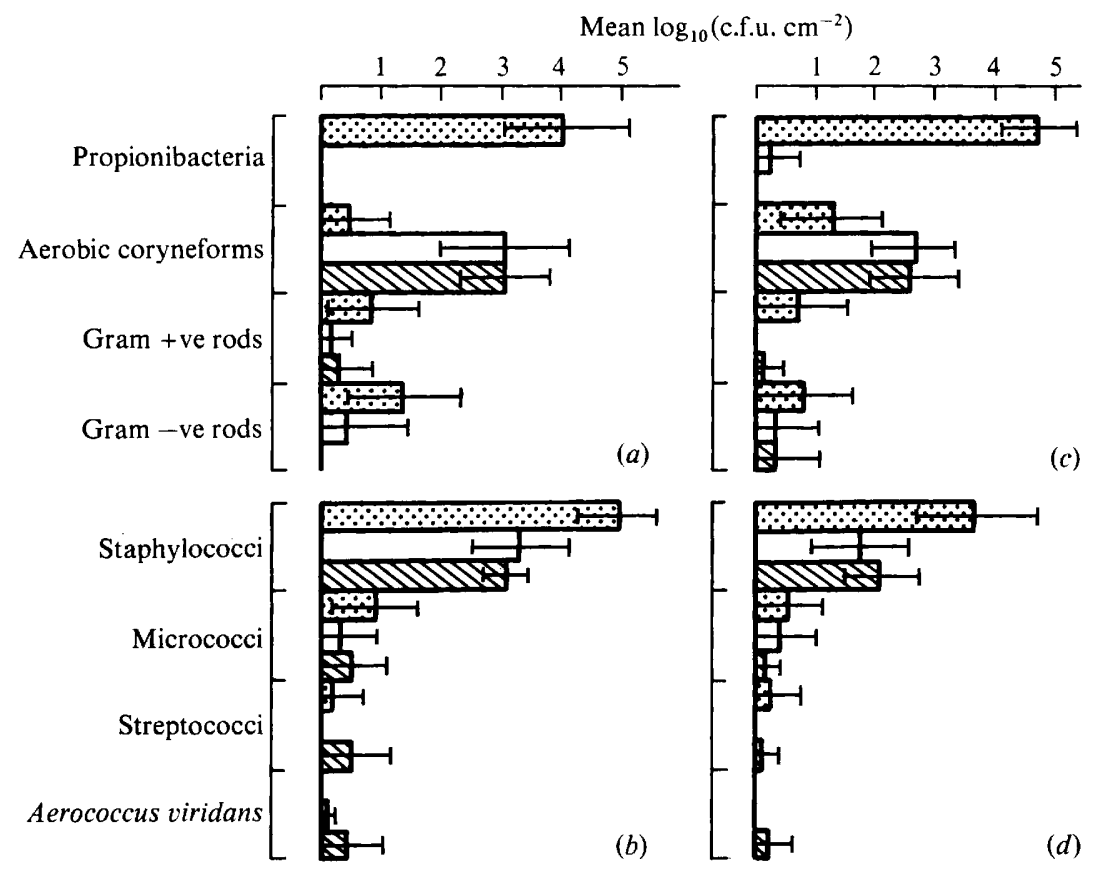

Fig. 2. Density of micro-organisms on human grafts and murine skin at $7 \mathrm{~d}(a, b)$ and $9 \mathrm{~d}(c, d)$ post grafting. Dotted bars represent human grafts, open bars anterior murine skin, and hatched bars posterior murine skin [mean $\log _{10}$ (c.f.u. $\mathrm{cm}^{-2}$ ) $\pm 95 \%$ confidence limits].

skin, and a low carriage of aerobic coryneforms, which constitute a major portion of the murine flora. Although all skin types exhibited a high carriage of staphylococci, the density was significantly greater on the human grafts (Fig. $2 b$ ). There was a difference in the carriage of Aerococcus viridans, which was not found on the grafted tissue (Fig. $2 b$ ), and a tendency for higher densities of Gram-positive and Gram-negative bacilli on the human grafts (Fig. $2 a$ ).

At $9 \mathrm{~d}$ post grafting (Fig. $2 c, d$ ) i.e. $2 \mathrm{~d}$ after the removal of the occlusive bandages, the microbial profile had changed only slightly. For the first time $P$. acnes was isolated from anterior mouse skin but at very low densities, whereas its density on the human skin remained high. The aerobic coryneform profile of the three skin types was similar to that observed at $7 \mathrm{~d}$, with murine skin maintaining a higher carriage. The staphylococci were most affected by the removal of the occlusive bandages. Their density decreased on all three skin types, although the 


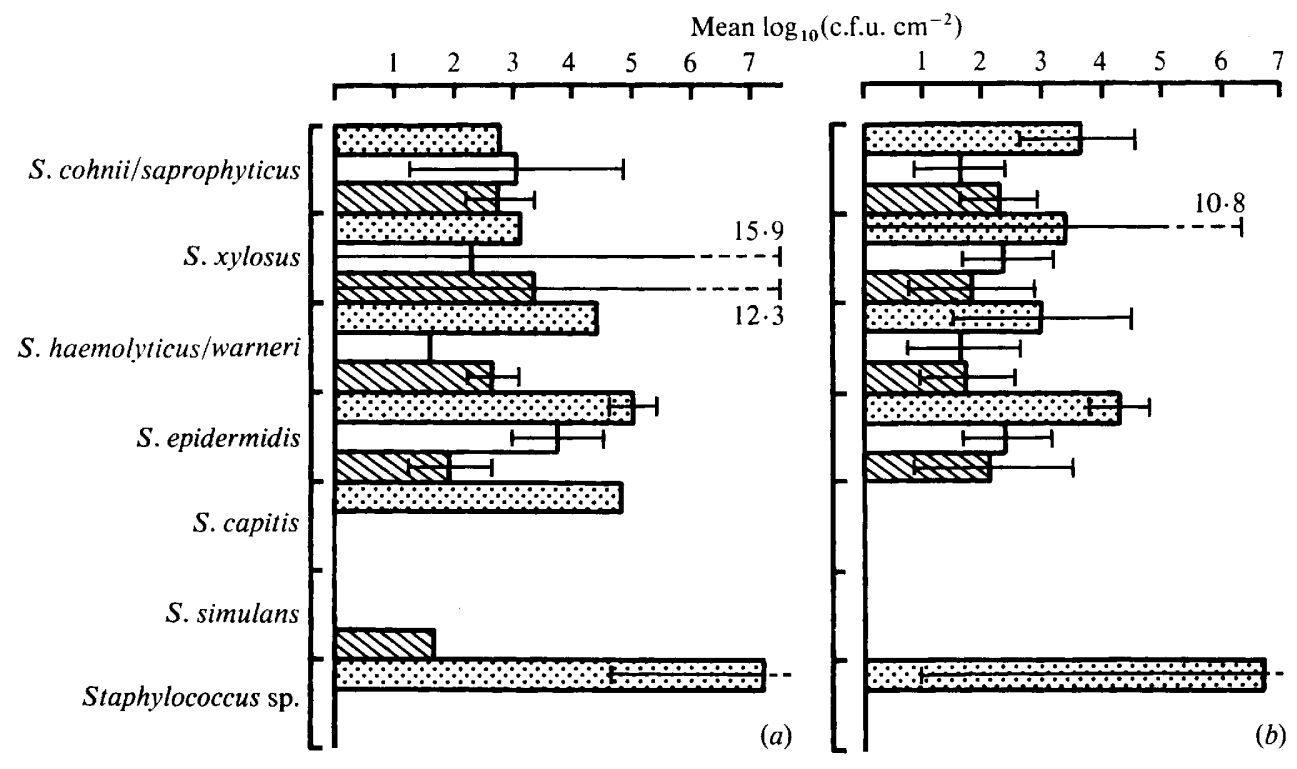

Fig. 3. Density of staphylococci on human grafts and murine skin at $7 \mathrm{~d}(a)$ and $9 \mathrm{~d}(b)$ post grafting. Dotted bars represent human grafts, open bars anterior murine skin, and hatched bars posterior murine skin [mean $\log _{10}$ (c.f.u. $\left.\mathrm{cm}^{-2}\right) \pm 95 \%$ confidence limits].

Table 1. Percentage incidence of Staphylococcus species on different skin types and at different intervals post grafting

\begin{tabular}{|c|c|c|c|c|c|}
\hline \multicolumn{3}{|c|}{$7 \mathrm{~d}$ post grafting } & \multicolumn{3}{|c|}{$9 \mathrm{~d}$ post grafting } \\
\hline $\begin{array}{c}\text { Human } \\
\text { graft }\end{array}$ & $\begin{array}{l}\text { Anterior } \\
\text { mouse skin }\end{array}$ & $\begin{array}{l}\text { Posterior } \\
\text { mouse skin }\end{array}$ & $\begin{array}{c}\text { Human } \\
\text { graft }\end{array}$ & $\begin{array}{l}\text { Anterior } \\
\text { mouse skin }\end{array}$ & $\begin{array}{l}\text { Posterior } \\
\text { mouse skin }\end{array}$ \\
\hline
\end{tabular}

S. cohnii/saprophyticus
S. xylosus
S. warneri/haemolyticus
S. epidermidis
S. capitis/hominis
S. simulans
Staphylococcus sp.

$\begin{array}{rr}4 & 50 \\ 4 & 20 \\ 4 & 10 \\ 87 & 80 \\ 4 & 0 \\ 0 & 0 \\ 9 & 0\end{array}$

83
17
33
42
0
8
0

17
8
17
83
0
0
8

Table 2. Temporal changes in the population densities of staphylococci and of P. acnes on human skin grafts

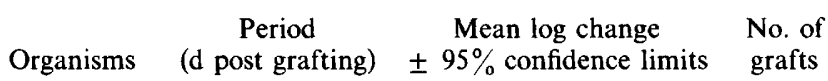

$\begin{array}{llrl}\text { (a) Staphylococci } & 0-7 & 1.64 \pm 0.66 & 23 \\ & 7-9 \text { (or } 10)^{*} & 0.76 \pm 0.70 & 31 \\ \text { (b) P. acnes } & 0-7 & -0.48 \pm 0.60 & 23 \\ & 7-9 \text { (or } 10)^{*} & -0.45 \pm 0.47 & 31\end{array}$

* Pooled data from grafts that were removed at either 9 or $10 \mathrm{~d}$ post-grafting.

higher carriage on human skin compared to mouse skin was maintained. Removal of the occlusive dressing did not significantly affect the carriage of other bacterial genera.

Comparison of the distribution and abundance of Staphylococcus species. The decrease in density of staphylococci was examined to determine whether there was a differential decline between Staphylococcus species (Fig. $3 a, b$ ). Because some of the species were isolated only once from the 
various skin types it was difficult to draw firm conclusions. In general, there did appear to be a decline in the density of all species on all skin sites after removal of the bandages. From the data at $9 \mathrm{~d}$ post grafting (Fig. $3 \mathrm{~b}$ ) it was also clearly established that the population density of each Staphylococcus species on human skin was one or two log cycles above that maintained on the mouse, whereas there was little difference between anterior and posterior mouse skin. On both human and murine skin the absolute density of each species (except for Staphylococcus sp.) was very similar within each skin type.

The percentage incidence of Staphylococcus cohnii/saprophyticus, Staphylococcus xylosus and Staphylococcus warneri/haemolyticus all increased slightly on the human grafts after removal of the dressing (Table 1), suggesting that they may be of murine origin. The incidence of Staphylococcus epidermidis on occluded mouse skin decreased at $9 \mathrm{~d}$, suggesting that occlusion may have selected for the establishment of this species.

Temporal changes in the density of propionibacteria and staphylococci on human skin grafts. The mean $\log _{10}$ change in the density of staphylococci with time is presented in Table $2(a)$. After $7 \mathrm{~d}$ occlusion the population had increased markedly, but exhibited a subsequent decrease after removal of the dressing. In contrast, the propionibacteria (Table $2 b$ ) showed a slight decrease in density at $7 \mathrm{~d}$ post-grafting, which was maintained during the following few days.

\section{DISCUSSION}

\section{Usefulness of the model system for studies on human cutaneous microbiology}

The establishment of a microbial ecosystem on a foreign host presented a number of potential problems. Firstly the host's flora might be inhibitory or be so numerous as to suppress the grafted flora. Alternatively, the murine flora might so closely resemble the graft flora that extensive strain typing would be required to establish whether micro-organisms taken from the graft were contaminants from the host. Finally, the grafting procedure itself or the change in the physiological environment might drastically alter the flora of the transplanted human skin.

With respect to the first of these possibilities, it was shown that, with the exception of the aerobic coryneforms, all bacterial groups were far less numerous on murine skin. There was no evidence of inhibition of the human flora, the relative densities remained consistent throughout the experimental period, and were in good agreement with the profile prior to grafting.

There was a degree of overlap with respect to the types of organisms present on the two skin types. Although aerobic coryneforms were present on both tissues, their density was initially very low on the human grafts and remained so, suggesting that contact with the high murine populations did not result in a large influx of transient mouse strains. There was an indication of a fall in the density of these bacteria during the $7 \mathrm{~d}$ of occlusion, however this could have been a result of competition from other aerobes, particularly staphylococci, which increased markedly. There was no evidence that occlusion per se was responsible, as the occluded murine skin showed no change in the density of aerobic coryneforms.

There was a larger degree of overlap in the genus Staphylococcus. Because of the importance of this genus in the human skin ecosystem and in causing skin diseases (Noble, 1981), more detailed taxonomic differentiation was carried out. On human skin the incidence of S. epidermidis was far higher than for any other Staphylococcus species both before (J. N. Kearney, G. Gowland, K. T. Holland \& W. J. Cunliffe, unpublished) and after grafting (Table 1). The murine skin, on the other hand, had a preponderance of the novobiocin-resistant group ( $S$. cohnii, S. saprophyticus and $S$. xylosus) and of $S$. haemolyticus/warneri. Sta.hylococcus epidermidis was present, however, particularly under the occlusive conditions. For more detailed studies it might be possible to use phage typing or some other epidemiological markers (Jeljaszewicz, 1981) to differentiate between strains of different origin.

The predominant Propionibacterium on the sebaceous-rich areas of human skin, P. acnes, was not found to be a member of the normal cutaneous flora of hairless mice. Webster et al. (1981) have recently shown that $P$. acnes is not isolated from animals having a low level of triglycerides in their sebum, which includes mice. In view of the importance of $P$. acnes in the intra-follicular 
habitat, and its implication in the disease acne vulgaris (Cunliffe \& Cotterill, 1975), its absence from mouse skin is fortunate, for changes in the $P$. acnes density on grafts can be confidently attributed to changes in the populations of resident human strains.

The other bacterial groups were not numerically important on either human or murine skin, and many of these have not traditionally been regarded as residents (Noble, 1981). Nevertheless, the model should provide a basis for studying the factors which elevate these transient or infrequent species to the status of opportunistic pathogens, resident within lesions (Fulton et al., 1968).

In conclusion, the murine flora does not inhibit, nor does it particularly resemble the human skin flora. Even after grafting, the human skin maintains its characteristic microbial profile.

\section{Ecological observations}

Although the primary objective of the work was to assess the usefulness of the model for studying human cutaneous microbiology, a number of observations were made relating to the ecology of skin micro-organisms.

Patterns were observed in the population density attained by different Staphylococcus species. After the bandages were removed and the system was allowed to equilibrate, there appeared a consistent difference in the capacity of the mouse and human environments to support each Staphylococcus species. In contrast, for any one skin type there was a remarkable similarity in the density of each species. This suggests firstly, that human skin provides a more favourable habitat for all species of staphylococci (or simply a larger habitat), and secondly, that the many physiological differences between species had no effect on the density attained, although they may have affected their rate of establishment and competitive ability.

Temporal changes in the density of staphylococci and propionibacteria were determined by comparison with the human skin prior to grafting. It must be stressed that these levels should not themselves be regarded as the norm for human skin, as it is possible that the changes which occur after death may elevate or depress the normal carriage. Nevertheless the comparison should permit the recognition of gross changes. There was a rise in the density of staphylococci and this was predictable from previous studies using human volunteers (Marples, 1965). However, the densities rapidly returned towards normal levels on removal of the dressing. In contrast, the propionibacteria were little affected and maintained a fairly constant density, suggesting that the changes in hydration and temperature (Marples, 1965) associated with occlusion did not affect the $P$. acnes population.

There were neither quantitative nor qualitative changes in the flora of the grafted skin which could be attributed to the novel physiological environment in which the skin was placed. There were enormous differences in microbial carriage on different pieces of cadaver skin (as there are between normal healthy people), which were maintained on the novel host and cannot therefore be attributed to physiological factors independent of the skin itself. This implicates the skin tissue as the controlling agent of microbial populations, which would explain the resilience of the ecosystem to the perturbations introduced here. This also results in a stable and reproducible model system, one of the original objectives of the investigation.

We would like to thank Vick International and the Leeds Foundation for Dermatological Research for financial support.

\section{REFERENCES}

Aly, R., Maibach, H. I., Shinefield, H. R., Mandel, A. \& Strauss, W. G. (1974). Bacterial interference among Staphylococcus aureus in man. Journal of Infectious Diseases 129, 720-724.

Billingham, R. E. \& Medawar, P. B. (1951). The technique of free skin grafting in mammals. Journal of Experimental Biology 28, 385-402.

COVE, J. \& EADY, E. A. (1982). A selective medium for the isolation of cutaneous propionibacteria. Journal of Applied Bacteriology (in the Press).
Cunliffe, W. J. \& CotTerill, J. A. (1975). The Acnes: Clinical Features, Pathogenesis and Treatment. London: W. B. Saunders.

Fulton, J. E., MCGinley, K. J., Leyden, J. J. \& MARPLES, R. R. (1968). Gram negative folliculitis in Acne vulgaris. Archives of Dermatology 98, 349-353.

Holland, K. T., Roberts, C. D., Cunliffe, W. J. \& Williams, M. (1974). A technique for sampling microorganisms from the pilosebaceous ducts. Journal of Applied Bacteriology 37, 289-296. 
JeLJaSzEwicz, R. (editor) (1981). Staphylococci and staphylococcal infections. Chapter 1. Zentralblatt für Bakteriologie, Parasitenkunde, Infektionskrankheiten und Hygiene (I. Abteilung), Suppl. 10, 3-126.

KeLlUM, R. E. (1966). Isolation of human sebaceous glands. Archives of Dermatology 93, 610-612.

KLOOS, W. E. \& SchleIfER, K. H. (1975). Isolation and characterisation of staphylococci from human skin. II. Description of four new species: Staphylococcus warneri, Staphylococcus capitis, Staphylococcus hominis and Staphylococcus simulans. International Journal of Systematic Bacteriology 25, 62-79.

Levins, R. (1968). Evolution in Changing Environments. Princeton, N.J.: Princeton University Press.

LeYden, J. J. \& MaRPLes, R. R. (1973). Ecologic principles and antibiotic therapy in chronic dermatoses. Archives of Dermatology 107, 208-211.

LEyden, J. J. MCGinley, K. J., Mills, O. H. \& KLIGMAN, A. M. (1975). Age-related changes in the resident bacterial flora of the human face. Journal of Investigative Dermatology 65, 379-381.

MARPLES, R. R. (1965). The effect of hydration on the bacterial flora of the skin. In Skin Bacteria and their Role in Infection, pp. 33-41. Edited by H. I. Maibach \& G. Hildick-Smith. New York: McGraw-Hill.
Marples, R. R. \& MCGinley, K. J. (1974). Corynebacterium acnes and other anaerobic diphtheroids from human skin. Journal of Medical Microbiology 7 , 349-357.

Noble, W. C. (1981). Microbiology of Human Skin. London: Lloyd-Luke.

Puhvel, S. M., Reisner, R. M. \& Amirian, D. A. (1975). Quantification of bacteria in isolated pilosebaceous follicles in normal skin. Journal of Investigative Dermatology 65, 525-531.

Shaw, C. M., Smith, J. A., McBride, M. E. \& DuNCAN, W. C. (1970). An evaluation of techniques for sampling skin flora. Journal of Investigative Dermatology 54, 160-163.

Somerville, D. A. \& Noble, W. C. (1973). Microcolony size of microbes on human skin. Journal of Medical Microbiology 6, 323-328.

Webster, G. F., RugGIERI, M. R. \& MCGINLEY, K. J. (1981). Correlation of Propionibacterium acnes populations with the presence of triglycerides on nonhuman skin. Applied and Environmental Microbiology 41, 1269-1270.

Williamson, P. \& Kligman, A. M. (1965). A new method for the quantitative investigation of cutaneous bacteria. Journal of Investigative Dermatology 45, 498-503. 